\title{
NECESSIDADE SIMPLES, NECESSIDADE COMPLEXA E ACIDENTE
}

Simple need, complex need and accident

Jaqueline Stefani *

Resumo: É aparentemente clara a posição de Aristóteles sobre o conhecimento científico ao negar que possa haver ciência do que é mutável. A ciência apresenta a causa e trata do necessário, daquilo que não pode ser diferente do que é. Todavia, em Segundos Analíticos I 30, Metafísica $\mathbf{k} 8$ e E 2, Retórica I 10 e Primeiros Analíticos I 27, eventos cuja ocorrência não é nem necessária, nem acidental, mas

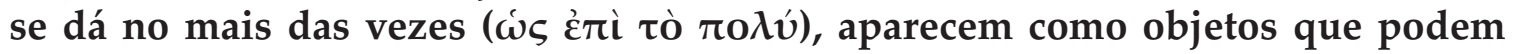
ser analisados cientificamente.

Palavras-chave: Aristóteles. Ciência. Necessidade Simples. Necessidade Complexa. Acidente.

Abstract: Aristotle's position about the scientific knowledge is evidently clear when he denies that there might be science of mutable things. Science presents the cause and deals with the necessary, things that cannot be different from what they are. However, in Posterior Analytics I 30, Metaphysics K 8 and E 2, Rhetoric I 10 and Prior Analytics I 27, events whose occurrence is not necessary or ac-

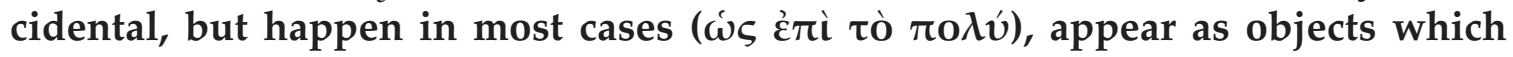
can be analyzed scientifically.

Key-words: Aristotle. Science. Simple Necessity. Complex Need. Accident.

* Professora do Programa de Pós-Graduação em Filosofia da Universidade de Caxias do Sul. Artigo recebido no dia 03/10/2014 e aprovado para publicação no dia 16/05/2015. 
sabido de modo incontroverso que, para Aristóteles, uma demonstração científica contêm premissas cujos predicados pertencem não acidentalmente, mas necessariamente aos sujeitos. ${ }^{1}$ Os silogismos científicos apresentam, igualmente, conclusão necessária e termo médio necessário. ${ }^{2}$ Aristóteles distingue, em Segundos Analíticos I 4, três condições encerradas pelos termos presentes na predicação: "de todo" ( $\kappa \alpha \tau \dot{\alpha}$

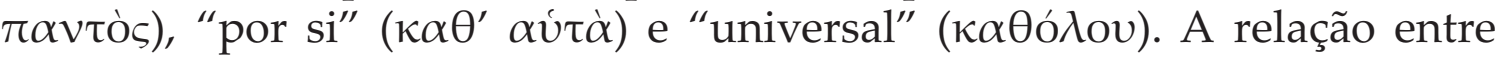
sujeito e predicado deve ser regida pelas três para que se obtenha premissa necessária no sentido prescrito por Aristóteles ao silogismo científico. "De todo" é um requisito que diz respeito ao sujeito da proposição sob o aspecto da extensão. Tal predicado é aquele que, independentemente do tempo e do lugar, se aplica a todos os indivíduos de uma classe. "Por si" é aquele que se refere ao sujeito sob o aspecto da compreensão. Tal predicado apresenta a essência, a definição e pode ser de dois tipos: ou ele contém o sujeito, ou está contido no sujeito. ${ }^{3}$ Assim, temos uma predicação "por si" se e somente se o predicado é elemento da definição do sujeito ou o sujeito é um elemento da definição do predicado, conforme Segundos Analíticos I 6 74b 5-10.

\footnotetext{
${ }^{1}$ Angioni (2004, p. 13) enaltece, com acerto, a necessidade referida à relação entre sujeito e predicado no conhecimento científico "no momento em que Aristóteles procura determinar a natureza das premissas do conhecimento científico [...] busca discernir os tipos de premissas ou proposições em que seja necessária a conexão entre sujeito e predicado".

${ }^{2}$ Cfe. Segundos Analíticos I 6 75a 10.

${ }^{3}$ Aristóteles apresenta, de fato, quatro acepções de por si em Segundos Analíticos, I 4, ao analisar as condições necessárias às proposições científicas, e diz explicitamente que as duas primeiras acepções se referem à ciência. No que se refere às duas primeiras acepções, a saber, aquelas em que ou o predicado contém o sujeito ou o sujeito está contido no predicado, não há controvérsia interpretativa relevante. Todavia, no que tange às últimas duas, as divergências existem. Questiona-se, por exemplo, se a terceira e a quarta acepções seriam compatíveis com a necessidade por si requerida pelas premissas do silogismo científico. $\mathrm{Na}$ sequência de Segundos Analíticos, especialmente em I 6, não há mais menção aos últimos dois tipos de por si parecendo que não são tipos compatíveis com proposições científicas. Porchat $(2001,2004)$ afirma que a terceira acepção seria restrita à metafísica, à ciência do ser enquanto ser e, portanto, estaria excluída da ciência, ao passo que a quarta acepção seria igualmente alheia à ciência por se tratar antes de uma relação predicativa sobre eventos cuja ocorrência é acidental. Angioni (2004), por outro lado, empenha-se em mostrar que a quarta acepção se reduziria às duas primeiras (p. 15) e seria, portanto, igualmente compatível com proposições científicas, ainda que concorde sobre o fato de Aristóteles não dizer explicitamente que tal seja o caso: "Aristóteles não afirma enfaticamente que a quarta acepção está incluída no domínio da ciência, mas também não afirma que ela está excluída desse domínio. A questão deve ser decidida por evidências complementares". (p. 21). Para fundamentar seu ponto, Angioni recorre à expressão "no mais das vezes" e conclui que a ciência aristotélica não é, em certo sentido, tão diferente da ciência moderna. Neste artigo, todavia, tomarei as duas primeiras acepções de por si como as relevantes ao conhecimento científico, no sentido em que se configuram em condições necessárias às premissas do silogismo demonstrativo.
} 
O segundo caso de predicado "por si" merece mais atenção. Aristóteles diz que, nesse sentido, predicado "por si" é aquele que contém seu sujeito como elemento em sua própria natureza pelos opostos, a saber, ou tais atributos são, para um sujeito determinado, necessários ou os seus opostos o são. O exemplo para esse caso é, para o sujeito "número", o predicado "par". É interessante perceber que não se trata do primeiro tipo de necessário "por si", o qual apresenta a essência. Evidentemente, "par" não é a essência de "número". A necessidade não é contínua, nem absoluta, pois um número pode ser ímpar, caso em que o oposto lhe é necessário. Assim, parece acertado entender que um predicado necessário na segunda acepção do termo "por si" é ou um predicado por propriedade ${ }^{4}$ ou é necessário, mas disjuntivo, no sentido em que ou um termo ou o seu oposto lhe será necessário.

Um pouco mais adiante, em Segundos Analíticos I 6 75a 15-20, diz Aristóteles que tem-se um predicado universal apenas quando ele se predica de todos os que caem sob a extensão do sujeito, por si e enquanto tal. Tal acréscimo é necessário, já que não basta saber que todos os indivíduos de uma classe possuem determinada característica; é necessário, ainda, saber que tal predicado se aplica à totalidade "por si" e enquanto tais sujeitos são o que são, segundo sua essência. Ou seja, é necessário que tal predicado se predique não acidentalmente, mas necessariamente ao sujeito, enquanto sujeito.

O exemplo do triângulo apresentado por Aristóteles em Segundos Analíticos I 5 74a 25-30 parece uma evidência de grande auxílio no tocante à compreensão da necessidade da tríade predicativa aludida ( $\kappa \alpha \tau \dot{\alpha} \pi \alpha v \tau o ̀ s$, $\kappa \alpha \theta^{\prime} \alpha \dot{\tau} \tau \dot{\alpha}, \kappa \alpha \theta$ ódov), especialmente no que tange ao predicado universal. O exemplo é o seguinte: se se quer provar que todo triângulo tem seus ângulos iguais a dois retos, provando, para isso, que cada triângulo particular (isósceles, escaleno e equilátero) tem tal característica, não se estaria provando o universal "todo triângulo tem seus ângulos iguais a dois retos", a não ser de modo puramente sofístico. Isso ocorre porque tal saber seria apenas um conhecimento numérico de todos os indivíduos de uma classe e não um conhecimento do que é o triângulo em geral enquanto triângulo. Poderia parecer que, se se conseguisse verificar indutivamente todas as espécies de triângulo existentes e se todas elas tivessem a soma de seus ângulos iguais a dois retos, estar-se-ia de posse de uma proposição que poderia figurar como premissa em um silogismo demonstrativo. Ter-se-ia, nesse caso (se ele fosse bem sucedido, i.e. se realmente não existisse outro

\footnotetext{
${ }^{4} \mathrm{O}$ predicado por propriedade, ainda que não apresente a essência, se predica apenas daquele sujeito e é convertível com ele, coextensivo, como os definitórios. A reciprocidade ou coextensibilidade entre sujeito e predicado é condição necessária para uma proposição definitória, mas não suficiente, pois é necessário ainda que tal predicado apresente a essência.
} 
triângulo que, até então, era desconhecido e que se apresentasse como exceção à regra), um predicado que se aplicaria a todos os triângulos, satisfazendo, aparentemente, o primeiro critério de predicado necessário: ser um predicado $\kappa \alpha \tau \dot{\alpha} \pi \alpha \nu \tau \dot{\alpha} \varsigma$, o qual se aplica extensivamente a todos os seus indivíduos, por exemplo, a isósceles, escaleno, etc. Mas isso não ocorre, pois uma demonstração segundo a forma não é apenas uma verificação exaustiva numérica de todos os itens.

Seguir-se-ia, então, na análise, talvez por desconfiar da simplicidade do primeiro critério predicativo necessário, e verificar-se-ia se tal predicado apresenta a essência. Ainda que "ter a soma de seus ângulos iguais a dois retos" pudesse ser considerado um predicado definitório para o sujeito "triângulo" e pudesse, por isso mesmo, responder adequadamente ao segundo requisito de predicado necessário, a saber, ser um predicado $\kappa \alpha \theta^{\prime}$ av́c่̀, apenas quando se sabe que tal predicado se aplica ao triângulo qua triângulo, i.e. em virtude da natureza específica do triângulo, é que se teria um predicado $\kappa \alpha \theta$ ó $\lambda$ ov em sentido estrito, a saber, no sentido em que compreende os três aspectos universais da necessidade; do contrário, tudo o que se saberá será meramente acidental ou sofístico. Isso porque não se trata de um critério quantitativo para alcançar o universal necessário, mas de uma necessidade que advém da própria natureza do predicado e do sujeito e é por essa necessidade que se aplica a todos, universalmente.

É interessante, nesse sentido, analisar um exemplo de Física I 8 191b 1: um médico, qua médico, construir uma casa é algo acidental, pois não é por ser médico que ele a constrói, da mesma forma que um escultor que cura a doença de alguém. A questão não é que isso não possa acontecer, mas que, se isso acontecer, não é por uma relação causal que acontece, pois o que há é mero acaso, coincidência. Assim, um predicado necessário, que contemple todos os critérios de universalidade (de todo, por si e universal), deve se referir ao sujeito enquanto o gênero que lhe é próprio e, enquanto gênero, a predicação "ter a soma de seus ângulos iguais a dois retos" atribuída ao triângulo, por exemplo, só cumpriria todos os requisitos individualmente necessários e conjuntamente suficientes se fosse tomada universalmente e vista sob o aspecto da essência. Dessa forma, a predicação universal não se refere ao isósceles, porque é isósceles, nem ao escaleno, por ser escaleno, mas ao triângulo qua triângulo, sob o ponto de vista de sua causa formal.

Os predicados $\kappa \alpha \theta^{\prime}$ dút $\dot{\alpha}$ requeridos pela ciência são universais em relação a seus indivíduos. O conhecimento superior é do universal e não do particular $^{5}$ e a ciência é sempre conhecimento do universal. ${ }^{6}$ Que o conhecimento do universal seja superior ao do particular é claro pelos seguintes motivos: i. o conhecimento da causa e do porquê são universais e são preferíveis ao

\footnotetext{
${ }^{5}$ Cfe. Segundos Analíticos I 24 85b 5-10.

${ }^{6}$ Cfe. Metafísica $\beta 4$ 999b 1.
} 
conhecimento do fato ou do que, meramente; ii. quem conhece o universal conhece, em alguma medida, o particular, ao passo que quem conhece o particular pode desconhecer totalmente o universal. ${ }^{7}$

São constantes as afirmações de Aristóteles sobre que, do ponto de vista da ciência, a demonstração se dá a partir do que é e não pode deixar de ser, como em Segundos Analíticos I 4 73a 20 e I 6 74b 5, ou em Ethica Nicomachea VI 3 1139b 20. A necessidade, então, é indispensável à ciência, seja na relação entre sujeito e predicado expressa nas premissas e na conclusão, seja para a inferência da conclusão como decorrente das premissas. Mas, e aquilo que não ocorre sempre, invariavelmente, mas também não é fruto do acaso? Inicialmente parece que ocorrências no mais das vezes

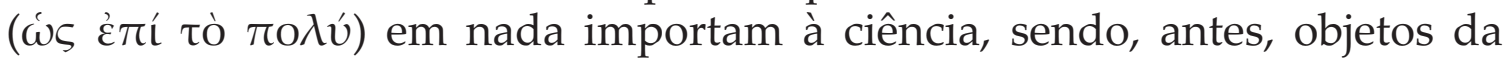
dialética e da retórica. Todavia, em Segundos Analíticos I 30, tal tipo de ocorrência aparece ao lado do necessário sem mais, como partícipe do silogismo científico e como categoria oposta ao acidental, àquilo que ocorre meramente por acaso:

Do que ocorre por acaso, não há ciência por demonstração. Com efeito, o que ocorre por acaso não ocorre nem necessariamente nem na maior parte


Todo silogismo [científico], com efeito, se faz de premissas necessárias ou que são verdadeiras a maior parte do tempo. [...]. De sorte que se o que ocorre por acaso não ocorre nem na maior parte do tempo nem necessariamente não haverá [disso] demonstração.

Lê-se em Metafísica k 8 1065a 1-5 que a ciência se ocupa: “ou do que é

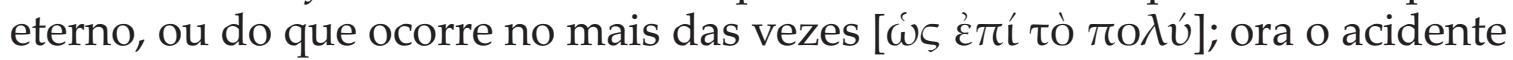

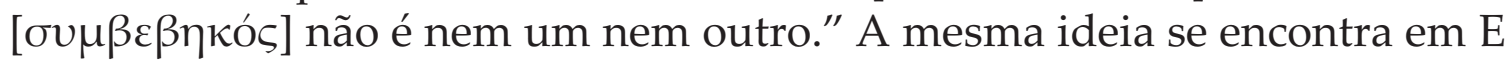
2 1027a 15-25 e em Retórica I 10 1369a 30. Em Primeiros Analíticos I 27 43b 30-35, lê-se que "se deve apreender também o que se produz de maneira

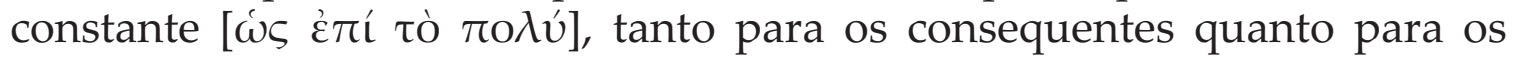
antecedentes. Com efeito, as conclusões sobre fatos constantes procedem também de silogismos em que todas as premissas, ou ao menos algumas, referem-se elas mesmas a fatos constantes".

Como conciliar estes dois âmbitos de eventos tão distintos - eventos no mais das vezes e eventos eternos -, ambos pertencendo ao âmbito científico e ambos opostos ao acidental? Não há como ignorar essas passagens, nem como negar que a inclusão desse novo objeto de conhecimento científico cause um estranhamento, dado o rigor da teoria do silogismo apresentada

${ }^{7}$ Cfe. Segundos Analíticos I 24 86a 20-30. 
até então. Haveria uma contradição interna à concepção da demonstração científica produzida pelo filósofo? Como entender a inserção do frequente, do constante, em um pano de fundo científico tecido sobre o necessário, o verdadeiro e o eterno que não admite mudança?

Barnes (2009, p. 343, 344), sobre isso, afirma o seguinte:

nos Analíticos as coisas [análises sobre o que ocorre no mais das vezes] são decepcionantes, e por várias razões. Primeiramente, a sugestão de que o elo entre premissas e conclusão poderia valer apenas na maior parte dos casos nunca é elaborada e nem mesmo sugerida. (Poderíamos plausivelmente suspeitar que ela faz apenas uma aparição fantasmagórica na Retórica). [...]. Em terceiro lugar, as poucas coisas que Aristóteles diz sobre as deduções 'na maior parte' não têm sistematicidade e são de validade duvidosa.

O comentário de Barnes parece se respaldar em um enfoque equivocado sobre a compreensão do objeto cuja aplicação valeria apenas no mais das vezes. Uma coisa é o frequente ser aplicado ao "elo" entre premissas e conclusão, à inferência propriamente dita, e outra é ser frequente a ocorrência de um predicado a um sujeito, que é apresentada nas premissas e na conclusão. A ligação entre premissas e conclusão não é frequente, mas necessária, por isso Aristóteles não escreve em momento algum que sejam frequentes, como bem constata Barnes. A necessidade lógica da inferência, tanto no silogismo frequente quanto no silogismo necessário em sentido absoluto, é a mesma. Por outro lado, parece acertado afirmar, como Barnes, que Aristóteles pouco fala sobre as deduções "na maior parte", mas daí a terem tais deduções "validade duvidosa", é outra questão.

O que me parece claro, em todo o caso, é que há duas alternativas pos-

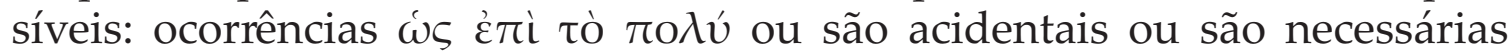
e, se acidentais, então não podem figurar como objetos de demonstração científica, em sentido estrito; por outro lado, se são necessárias, há que se estabelecer que tipo de necessidade é essa, tendo em vista que não parece se tratar daquela necessidade sem mais, absoluta, tantas vezes realçada na teoria aristotélica da ciência.

É moeda corrente entre os intérpretes de Aristóteles apresentar os vários sentidos de um termo quando tal termo é central em uma investigação qualquer. Assim, seguidamente se retoma os vários sentidos de necessário, acidental, princípio, causa, etc. Todavia, o termo contingente não recebe, geralmente, a mesma atenção e é utilizado com frequência como oposto ao necessário, sem maiores especificações. Entretanto, ao que parece, uma das acepções de contingente figura na teoria aristotélica da ciência, exatamente no registro do frequente. Em Primeiros Analíticos I 13, após apresentar de 
forma clara e completa em que medida a ciência diz respeito ao que é necessário, Aristóteles esclarece em que casos o que não é necessário em sentido absoluto, mas contingente, pode ser objeto do silogismo demonstrativo. O contingente compreende duas acepções: como indeterminado, no sentido em que pode, igualmente, tanto ocorrer quanto não ocorrer, e como o que geralmente ocorre, o que pertence naturalmente a algo, ainda que careça de necessidade contínua, absoluta, simples, sem mais. Os exemplos para ambos os casos são esclarecedores. Para o contingente tomado como indeterminado o exemplo é a ocorrência de um tremor de terra enquanto um animal caminha. Para o contingente na segunda acepção (como o que frequentemente ocorre) um exemplo é o crescer ou o envelhecer para um homem:

A expressão "ser contingente" se diz de dois modos. Em um primeiro

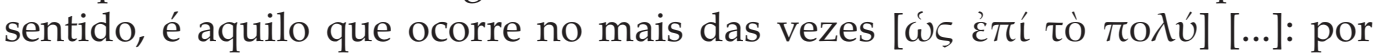
exemplo, para o homem, ficar grisalho, crescer, decrescer ou, de um modo geral, o que lhe pertence naturalmente (isso, com efeito, não tem uma necessidade contínua, pois o homem não existe sempre, mas, se o homem existe, tais determinações se produzem seja necessariamente, seja no mais das vezes). Em outro sentido, o contingente é o indeterminado, o que pode ser às vezes assim e não assim: por exemplo caminhar, para um animal, ou ainda, que um tremor de terra se produza durante sua caminhada, ou, de um modo geral, o que ocorre por acaso. (Primeiros Analíticos I 13 32b 5-15).

O que interessa aqui, exatamente porque parece dizer respeito à ciência aristotélica juntamente com o necessário em sentido absoluto, é o contingente tomado no primeiro sentido. Tanto pelos exemplos - ficar grisalho, crescer e envelhecer em relação ao homem -, quanto pela característica geral - o que lhe pertence naturalmente - parece claro que a única diferença entre tal tipo de ocorrência, se comparada com o que é necessário em sentido absoluto, é que, no primeiro caso, é possível que alguns indivíduos contidos no universal "homem" possam não apresentar tais características (ficar grisalho, crescer e envelhecer), o que não ocorre caso o evento seja necessário em sentido absoluto. Mas cabe verificar em que casos o que pertence naturalmente a algum sujeito pode vir a não se manifestar, ou, conforme os exemplos, em que casos um homem não cresce ou não envelhece. A importância de tal análise é central, pois é por meio dela que será possível perceber a diferença entre o frequente e o necessário em sentido absoluto.

Aristóteles diz que nesses casos em que a ocorrência é constante ou natural a necessidade não é absoluta. ${ }^{8} \mathrm{E}$ ela não é absoluta simplesmente porque o

\footnotetext{
${ }^{8}$ No $D A$ (III 12, 434a 20), lê-se que: “Todo aquele que vive e tem alma, então, é necessário que tenha a alma nutritiva - do nascimento até a morte. Pois é necessário que o que nasceu tenha crescimento, maturidade e decaimento, e tais coisas são impossíveis sem nutrição. Logo, é necessário que a potência nutritiva esteja em todos aqueles que crescem e decaem". [grifo meu].
} 
homem não existe sempre, ou, em outras palavras, nem sempre o homem chega à idade em que tais atributos lhe seriam predicáveis. Tal homem poderia morrer antes, e.g. em um acidente. Todavia, se o homem chegar à idade em que isso ocorre, tais características (ficar grisalho, crescer e envelhecer) irão se manifestar necessariamente. Dito de outro modo: sempre que não houver qualquer impedimento, tal evento vai ocorrer. Entende-se, assim, que o frequente não se opõe ao necessário, mas lhe é aparentado e ambos são objetos da ciência. ${ }^{9}$

A questão central parece ser que, em ambos os casos, opera um tipo de necessidade: em eventos que ocorrem sempre e invariavelmente, ${ }^{10}$ a necessidade é absoluta, independente das circunstâncias; em eventos que ocorrem no mais das vezes, a necessidade envolvida é de outro tipo, condicionada, no sentido em que, dadas certas circunstâncias, o evento ocorrerá sempre e necessariamente. Chamarei o primeiro tipo de necessidade simples (sem mais) e o segundo de necessidade complexa, por envolver uma dependência em relação às circunstâncias, as quais podem impedir a natureza de se manifestar.

Aristóteles diz que, assim como o que é necessário absolutamente e ocorre sempre, o que é contingente no sentido do que naturalmente ou geralmente ocorre, e não no sentido de indeterminado, diz respeito à ciência:

Não há ciência nem silogismo demonstrativo de coisas indeterminadas, em razão da instabilidade do meio termo, mas somente de coisas naturais, e se pode dizer que as discussões têm por objeto apenas as coisas que são contingentes neste último sentido. (Primeiros Analíticos I 13 32b 15-20).

Parece-me que há mais de uma maneira de analisar a relação entre necessário e contingente. Necessário é entendido, principalmente, em dois sentidos: i. em sentido absoluto, quando a coisa não pode ser diferente do que é; tal é a característica de eventos que ocorrem sempre e invariavelmente, independentemente das circunstâncias, pois decorrem da natureza própria do objeto (a matemática é a ciência exemplar desse caso); ii. em sentido condicionado, no sentido em que, se nada impedir sua ocorrência, o evento ocorrerá sempre e necessariamente, ${ }^{11}$ tal é o caso do frequente e

\footnotetext{
${ }^{9}$ Sobre isso ver artigo de Paulo Ferreira intitulado "Notas sobre a definição do enunciado asseverativo em Aristóteles", p. 10, onde apresenta e analisa as posições de Alexandre e de Porfírio sobre essa passagem aristotélica acerca das duas acepções de contingente e o exemplo do predicado encanecer, aplicado ao ser humano.

${ }^{10}$ Assim entende Porchat, com razão, a necessidade dos eventos eternos que são objeto da ciência (2004, p. 133) "Eternas são, assim, as determinações quantitativas das coisas físicas que o pensamento matemático delas abstrai e separadamente estuda."

${ }_{11}$ Porchat $(2004$, p. 140, 141), parece pensar diferente: “[...] o que ocorre no mais das vezes não é necessário, as demonstrações que lhe dizem respeito não exibem causas que produzem necessariamente seus efeitos. A causalidade material, auxiliar, envolvida na geração dos seres naturais [...] tem a necessidade hipotética da condição para a realização de um fim; a ciência do objeto não pode, por isso mesmo, desconsiderá-la, mas não se define por ela".
} 
regular, como no caso do hidromel ser benéfico a quem tem febre e dos homens terem barba. Por outro lado, o contingente também é tomado em dois sentidos: i. como indeterminado, no sentido em que pode, igualmente, tanto ocorrer quanto não ocorrer (por exemplo, que ocorra um tremor de terra enquanto um animal caminha); ii. como o que geralmente ocorre, o que pertence naturalmente a algo, por exemplo, o crescer e o envelhecer para um homem. Nesse sentido, os homens frequentemente crescem e envelhecem, pois, ainda que o crescer e o envelhecer pertençam naturalmente à existência humana, isso pode não ocorrer se, por exemplo, um homem não viver o suficiente para tanto, ou seja, nem todo o homem vive o tempo necessário para crescer e envelhecer. Se não viver, foi devido à interferência de outros fatores que impediram o curso natural; se viver, crescer e envelhecer ocorrerão, necessariamente. Entende-se que necessário em sentido absoluto se opõe totalmente a contingente no sentido de indeterminado. Mas o evento frequente, que se entende como objeto da ciência, tem a característica tanto do necessário em sentido condicionado, quanto do contingente no sentido do que naturalmente ocorre.

A menção ao frequente na Física, nesse sentido, requer atenção especial. Afirma Aristóteles ${ }^{12}$ que alguns entes ocorrem ou têm sua causa por natureza, como os animais e as plantas. Esses entes que são por natureza têm em si mesmos o princípio de movimento e de repouso, como o crescer e o definhar. ${ }^{13}$ Além disso, a natureza é sempre em vista de algo. Ora, o que frequentemente ocorre é por natureza e, consequentemente, em vista de algo. Afirma Aristóteles que, das coisas que se geram, umas são por natureza, outras por arte e outras por acaso. Todas as coisas que se geram e são por natureza, são em vista de algo:

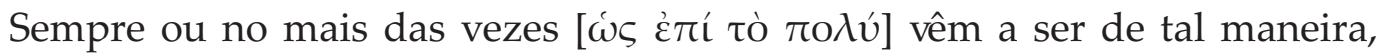
mas, entre as coisas que são por acaso ou pelo espontâneo, nenhuma vêm a ser assim. De fato, não se julga que é por acaso ou coincidência que chove muitas vezes no inverno, mas sim se chove durante a canícula; tampouco se julga que o calor durante a canícula é por acaso ou coincidência, mas sim se for no inverno. Ora, dado que se julga que tais coisas são ou por coincidência ou em vista de algo, se não é possível que elas sejam nem

\footnotetext{
${ }^{12}$ Física II 1 192b 8.

13 “Natureza é isso que foi dito; por sua vez, tem natureza tudo quanto tem tal princípio. Todas essas coisas são substância, pois são um subjacente, e a natureza sempre reside num subjacente. São 'conforme à natureza' tais coisas e tudo que lhes pertence devido a elas mesmas - por exemplo, para o fogo, locomover-se o alto: de fato, isso não é natureza, nem tem natureza, mas é por natureza e conforme à natureza." (Física II 1 192b 32).
} 
por coincidência nem pelo espontâneo, resta que elas são em vista de algo. Pois bem: todas as coisas desse tipo são por natureza [...]. Portanto, o em vista de algo está presente nas coisas que são e vêm a ser por natureza. (Física II 8 198b 35).

A necessidade e a finalidade se encontram sempre próximas e a natureza é regida por um fim próprio. ${ }^{14} \mathrm{O}$ que é por natureza e em vista de algo deve ocorrer, a menos que as condições adequadas não sejam obtidas, ou que algo impeça sua finalidade intrínseca de se manifestar, pois natureza, além de ser causa material, eficiente e formal, é causa final: "Assim mesmo é que por natureza surge, e assim como surge por natureza, do mesmo modo se faz cada coisa, se algo não impedir." (Física II 8 199a 10). A teleologia na natureza, quando ocorre no mais das vezes, é porque algo externo impediu sua atualização: "Quanto aos seres naturais, que tem em si mesmos o princípio de sua atualização, eles serão em potência outra coisa por si mesmos, se nada de exterior impedir" (Metafísica $\Theta 7$ 1049a 10-15). Em $D A$, diz Aristóteles que a matéria é potência, ao passo que a forma é atualidade (II 1 412a 10) e que "a atualidade de cada coisa ocorre por natureza na matéria apropriada e em sua potência subsiste." (II 2 414a 20).

Na Física, o objetivo de Aristóteles é delimitar as causas que vigoram no domínio dos fenômenos naturais e os princípios pelos quais eles podem ser cientificamente conhecidos. O que é por natureza tem em si mesmo o princípio do movimento (causa eficiente), é em vista de algo (causa final) e se dá como matéria e forma. Dessa forma, no contexto das ciências naturais, nem a matéria nem a forma podem existir separadamente.

Em EN, lê-se que as coisas que são sujeitas à mudança são aquelas que não são por natureza. Assim, no contexto da virtude moral, por exemplo, diz Aristóteles que tal virtude não se engendra em nós naturalmente, pois nada do que existe por natureza pode ser diferente (II 1 1103a 15-25). Para coisas que são por natureza, os exemplos apresentados são o mover-se para baixo, para a pedra, e o mover-se para cima, para o fogo. Dessa forma, o que não é por natureza é passível de alteração, diferente do que é por natureza e envolve necessidade, ainda que existam casos em que a natureza não possa realizar suas intenções, sua teleologia, i.e. casos em que a natureza, a finalidade e, portanto, a necessidade, por terem sido interrompidas de algum modo, não ocorram.

\footnotetext{
${ }^{14}$ Assim se expressa Porchat, sobre o processo teleológico da natureza "[...] os dentes e as coisas da natureza, em geral, se produzem ou sempre ou na maior parte das vezes do mesmo modo e isso não ocorre com o que provém da sorte ou do acaso; não se pensa que decorra da mera coincidência (apò toû symptómatos) ou da sorte o fato de que chova com freqüência no inverno, ou o calor durante a canícula. Ora, se o que vem a ocorrer ou é produto da coincidência ou se dá em vista de um fim, aqueles processos naturais não podendo provir nem da coincidência nem do acaso, se dão, então, em vista de um fim. Há, portanto, uma finalidade nas coisas que naturalmente vêm a ser e são". (Porchat, 2004, p. 131, 132).
} 
Conforme Zingano, a expressão por natureza admite quatro sentidos em Aristóteles, referindo-se à análise feita por Aspásio:

(i) o que sempre ocorre para algo, como o pesado, que se move sempre para baixo; (ii) o que não existe desde o início, mas que, com o tempo, ocorre nas mais das vezes, como o surgimento dos dentes; (iii) aquilo de que somos receptivos, como a saúde e a doença, contrários quanto ao corpo, e (iv) aquilo de que somos receptivos e para o qual temos uma propensão, como a saúde, em relação à qual a doença é contrária à natureza. $(2008$, p. 94, 95).

Zingano segue dizendo que, no contexto da Ethica Nicomachea referido acima (II 1 1103a 15-25), segundo Aspásio, o sentido da expressão por natureza, referido à virtude, é o sentido (iii) e (iv); todavia, nos sentidos (i) e (ii) a virtude não é por natureza. Ora, se a virtude fosse por natureza nos sentidos (i) e (ii), ela não seria passível de mudança, pois há uma necessidade, nesses dois sentidos, de que as coisas ocorram dessa forma. Entendo que o sentido de por natureza, quando referido ao frequente, é, sobretudo, o sentido (ii), pois é o que ocorre no mais das vezes e se aplica a casos como o surgimento dos dentes nos humanos, o aparecimento de barba no homem ou o crescer e envelhecer referido ao ser humano, tendo, por isso, um caráter de necessidade.

A teoria da ciência estabelecida por Aristóteles, principalmente em Analíticos Posteriores, pareceria distante demais da Física e das ciências da natureza, segundo alguns comentadores. No entanto, entendo que: i. o frequente tem a característica de necessidade (ainda que complexa), assim como o que sempre ocorre (em sua necessidade simples, absoluta); ii. ambos, caracterizados respectivamente por necessidade complexa e necessidade simples, são objetos da ciência, contrários ao que acontece por mero acaso, por coincidência; iii. os fenômenos naturais, que ocorrem com frequência, assim compreendidos, podem ser cientificamente estudados, pois contêm necessidade; iv. tal conhecimento dos fenômenos naturais é consistente, apesar do movimento e do devir que os acometem, donde decorre que v. não há discrepância entre a Física e as demais ciências com relação à teoria apresentada nos Analíticos; o que há é uma diferença na natureza da necessidade que compete a cada uma delas.

A diferença entre o conhecimento matemático e o conhecimento das ciências da natureza possibilita que se veja com maior acribia a inserção do frequente na ciência e a importância do movimento e da matéria em tal inserção. Isso porque a Matemática é a ciência que Aristóteles parece ter em mente como ciência exemplar, quando se refere ao silogismo 
demonstrativo exposto nos Analíticos. De acordo com a teoria aristotélica da ciência é incontroverso que todo aquele que conhece cientificamente algo conhece o porquê, as causas, os princípios desse algo. Mas, quando referido aos fenômenos naturais, é necessário que tal conhecimento se dê com base em causas apropriadas. $\mathrm{O}$ acaso, por outro lado, é indeterminado, instável, inconstante, sendo sua ocorrência mera coincidência. Por isso é que o acaso escapa ao âmbito da razão.

Parece inequívoco que Aristóteles conceba a Física em termos de conhecimento científico. ${ }^{15}$ Todavia, são distintas as ciências naturais e a matemática a respeito do modo de demonstração. A Física não pode ser entendida ao modo de um conjunto de proposições das quais teoremas sejam derivadas dedutivamente. Segundo Aristóteles (por exemplo, em Metafísica $\alpha 3$ 995a 15), o rigor matemático deve ser exigido apenas em coisas que são desprovidas de matéria. Ora, o objeto da Física é a natureza, e a natureza não é desprovida de matéria, por isso não se pode usar o método matemático na Física. A Física e a Matemática são conhecimentos teoréticos; à primeira cabe o estudo daquilo que tem movimento e é inseparável da matéria; à segunda cabe o estudo de realidades imóveis. Contudo, Aristóteles afirma que o necessário, nas ciências matemáticas, é similar ao necessário nas ciências da natureza. Isso porque a relação entre antecedente e consequente, que é uma relação explicativa, causal, é a mesma na matemática e nas ciências naturais. A necessidade lógica, nesse sentido, é a mesma em ambas as ciências. Tanto o estudioso da natureza, quanto o matemático, por exemplo, podem estudar a esfericidade da terra ou a lua e o sol. Entretanto, o matemático não investiga tais coisas enquanto corpos naturais, mas à parte de suas características naturais, de sua matéria, de sua mudança. Esses objetos são analisados em separado, abstratamente, e não como corpos naturais em movimento, mas os tomando como separados do movimento. Tal separação é operada pelo pensamento em uma atividade de abstração tornando possível a investigação do objeto em si mesmo, independentemente da matéria. ${ }^{16}$

Ora, segundo a concepção aristotélica, o conhecimento deve se adequar ao objeto e não se pode exigir o mesmo rigor em todos os casos por igual. $\mathrm{O}$ conhecimento não se obtém de um único modo nem por um único método. Deve haver uma adequação entre o método proposto, o objeto a ser investigado e o rigor que se pode exigir em cada caso. A $E N$, por exemplo, traz a ideia de que a tarefa de esclarecer algo é suficientemente

\footnotetext{
${ }^{15}$ Cf., por exemplo, Metafísica E 1 1025b.

16 "Mostram isso também as mais naturais entre as disciplinas matemáticas, como a ótica, a harmônica e a astronomia: de certo modo, elas se comportam de maneira inversa à geometria, pois a geometria estuda a linha natural, mas não enquanto natural, ao passo que a ótica estuda a linha matemática, não enquanto linha matemática, mas enquanto linha natural". (Física II 1 194a 7).
} 
realizada, se tal esclarecimento estiver de acordo com a natureza do objeto, pois o rigor depende do tipo de discussão empreendida (I 1, 1094b 10 e I 7, 1098a 25). Em outra passagem da mesma obra, Aristóteles afirma que saber o rigor que se pode exigir, dependendo do gênero de coisas que se está a investigar, é próprio do homem culto (I 1, 1094b 20-25). Na Metafísica (K 7, 1064a 5), lê-se que, nas ciências, procura-se demonstrar as conclusões com menor ou maior rigor, em outros termos, com o rigor que lhes é próprio.

De fato, Aristóteles é constantemente invocado, contemporaneamente, por essa distinção e especificação do tipo de rigor ou exigência que é razoável exigir, sempre de acordo com o caso em questão. O método empregado em qualquer tarefa investigativa deve estar de acordo com o objeto a ser analisado e de acordo com os resultados passíveis de serem extraídos em cada caso; assim, de premissas necessárias há que se ter conclusão igualmente necessária; de premissas prováveis, conclusão provável. Uma coisa é investigar um objeto conforme sua natureza e movimento, outra é estudá-lo separado do movimento. Se o objeto é eterno e imutável, sua ocorrência não depende das circunstâncias, de outras causas que não a sua própria natureza. Se, por outro lado, a natureza do objeto não é suficiente para garantir sua permanência e eternidade, sua ocorrência dependerá de circunstâncias conjugadas à sua natureza. No $D A$, lê-se que:

Para os que vivem [...] o mais natural dos atos é produzir outro ser igual a si mesmo; o animal, um animal, a planta, uma planta, a fim de que participem do eterno e do divino como podem. [...]. Ora, uma vez que é impossível compartilhar do eterno e do divino de maneira contínua - porque nada perecível admite perdurar uno em número e o mesmo -, no que cada um pode participar é compartilhando desta maneira. (II 4 415a 25-30).

Como em eventos naturais o objeto não é suficiente para garantir a ocorrência das condições adequadas, ele é frequente, regular e obedece à regra, dadas as condições adequadas. Há uma maleabilidade no rigor do conhecimento científico em ciências como a Harmônica, a Ótica e a Astronomia. Isso pode ser explicado lembrando que o rigor e a exatidão de uma ciência em relação à outra se referem à sua característica de anterioridade. Como as ciências são diferentes e tratam de assuntos diferentes, o rigor e a exatidão que se pode exigir em cada caso também serão diferentes. Assim também se deve proceder em relação ao que sempre ocorre e ao que ocorre frequentemente. Se se estuda o objeto em suas características imutáveis, em sua necessidade absoluta, o que se requer é uma demonstração com premissas e conclusão que compreendam ocorrências necessárias em sentido absoluto. Por outro lado, se se estuda o objeto da ciência como sua natureza mutável, então a demonstração requerida deverá compreender premissas e conclusão que tratem de ocorrências cuja necessidade envolvida seja complexa. Tal necessidade complexa requer que determinados fatores 
ocorram, de acordo com a materialidade e o movimento das coisas que se tem por objeto de investigação, coisas essas que participam do eterno e do divino "como podem".

No que se refere ao mundo supralunar, os objetos de estudo como o sol, os astros e o céu são sempre em ato e jamais em potência. ${ }^{17}$ Nesses casos, por suas características de necessidade simples, sem mais, e de eternidade, a ciência demonstrará a conclusão com igual necessidade. Por outro lado, como nada do que é em potência é eterno, e como a natureza sublunar é em potência, resta que desses eventos não se pode ter uma demonstração cujas premissas e conclusão tenham as mesmas características de necessidade e eternidade do mundo supralunar. A física trata de um domínio científico que exige uma regularidade e, por isso, uma necessidade. A

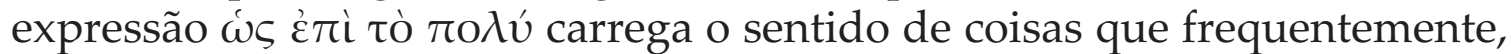
geralmente, naturalmente, constantemente ou no mais das vezes ocorrem. É uma expressão que substitui o necessário sem mais quando o objeto de estudo é aquilo que ocorre na natureza, servindo, portanto, às ciências da natureza. Dessa forma, pensa-se que a teoria da ciência aristotélica foi concebida como uma teoria mais alargada do que a que é geralmente apresentada. É uma ciência não fundada apenas no absolutamente necessário, mas que, devido à natureza dos objetos que se tem por investigar, pode ser mais flexível e abranger um campo maior de conhecimento, ainda que não destituído de necessidade.

A demonstração se refere tanto ao necessário sem mais, simples, quanto ao necessário complexo. Com efeito, todas as coisas naturais ocorrem ou sempre ou quase sempre, mas ambos os termos sempre e quase sempre se opõem aos acidentes, àquilo que ocorre meramente por acaso. Assim, se Aristóteles atribui uma necessidade incondicionada aos corpos celestes e aos objetos matemáticos, à natureza é atribuída uma espécie de necessidade que compreende a formação e a geração dos entes naturais. Dizer que algo ocorre no mais das vezes significa dizer que, ainda que tal evento não ocorra sempre, sempre que ele ocorre, ele ocorre dessa maneira. $\mathrm{O}$ que há de necessário no que ocorre no mais das vezes é o fato de que há um padrão na ocorrência e que é oposto, então, ao mero acaso. O acaso, assim como o acidente e o contingente (em seu sentido indeterminado), é o que pode ser de outra maneira, é aquilo que tanto pode ocorrer, quanto não ocorrer. Pensa-se que o frequente não se encaixa nessa concepção, que define, primordialmente, o acidental. ${ }^{18} \mathrm{O}$ frequente é regra, ainda que admita exceção. Todavia, a exceção, quando ocorre, ocorre porque algo externo ao fato o impediu de se realizar, interrompeu sua finalidade. Tal não efetivação pode ocorrer sempre que a necessidade de realização

\footnotetext{
17 Cfe. Metafísica $\Theta 81050 b$.

${ }^{18}$ Cfe. Metafísica E 2 1027a 10-15.
} 
for obliterada por algo, i.e. sempre que algo impedir que a potência se transforme em ato. Dessa forma, no caso do frequente, dadas todas as condições, sua ocorrência também não poderá ser de outra maneira, sendo, portanto, necessária. $\mathrm{O}$ acaso é inconstante e o que acontece sempre ou frequentemente é constante.

Assim, se por um lado há eventos que ocorrem sempre, o que ocorre com aqueles objetos que são eternos e imutáveis, por outro, há os eventos que ocorrem no mundo físico e que ocorrem com frequência, no mais das vezes. Em ambos os casos, Aristóteles se refere a ocorrências passíveis de serem demonstradas com o rigor do silogismo científico e em oposição ao mero acaso, ainda que haja uma diferença significativa em cada um desses silogismos: se parte de premissas frequentes, a conclusão será frequente; se parte de premissas necessárias, a mesma necessidade será seguida na conclusão. A exigência e o rigor necessários na demonstração dos eventos frequentes devem ser readequados, pois o mundo material concerne a eventos envolvendo uma gama maior de condições, além da natureza do próprio objeto, e que ocorrem, por isso mesmo, não invariavelmente, mas apenas na maior parte dos casos. ${ }^{19}$ A coerência aristotélica se mantém no que se refere à adequação interna ao silogismo, ${ }^{20}$ pois os primeiros princípios, as premissas deles derivadas e a conclusão devem acompanhar essa especificação: se o silogismo versa sobre o necessário em sentido absoluto, ambas (premissas e conclusão) devem seguir tal natureza e serem, também, necessárias em sentido absoluto; se o silogismo versa sobre o frequente, premissas e conclusão devem acompanhar essa natureza, assim como o termo médio. Dessa forma, é um erro confundir o que ocorre por acaso, o que ocorre sempre e o que ocorre frequentemente. ${ }^{21}$

Entretanto, em que casos haveria um silogismo científico não do que sempre ocorre, mas daquilo que frequentemente ocorre? Os exemplos aristotélicos são elucidativos:

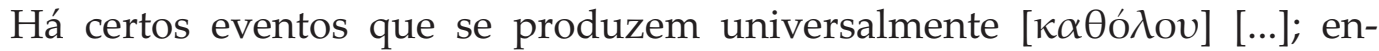
quanto outros não sempre, mas na maioria das vezes [w่s k̇ंì tò $\pi \mathrm{o} \lambda \hat{]}$,

\footnotetext{
${ }^{19}$ Hankinson escreve: “A razão pela qual certas coisas acontecem apenas na maior parte das vezes e não invariavelmente é, para ele [Aristóteles], o envolvimento da matéria delas no que acontece. [...] A matéria [...] é aquilo em que a forma é realizada e que permanece constante, ao menos em um sentido, em meio à mudança". (2009, p. 162-163).

${ }^{20}$ Cfe. Ethica Nicomachea I 1 1094b 20 e Segundos Analíticos II 12 96a 5.

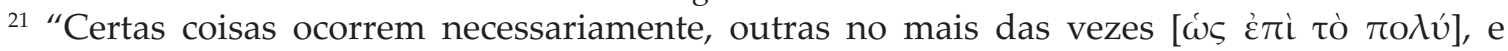
outras enfim em virtude de um acaso qualquer; se se põe o necessário como constante [ $\omega \varsigma$


si. Com efeito, se se põe o necessário como constante é evidente que se recusa a um atributo de ser universal, enquanto que ele universal, e assim se comete um erro; é igualmente um engano se se enuncia um atributo constante como necessário, porque se afirma sua atribuição universal, enquanto que ela não é universal. [...]. Isto é verdade também, se se toma o que ocorre por puro acaso como necessário ou constante, pois o que depende de um acaso qualquer não é nem necessário, nem constante". (Tópicos II 6 112b 1-15).
} 
por exemplo nem todo homem tem barba no queixo, mas isso acontece na maioria das vezes. Em casos desse gênero, pois, é necessário que o meio

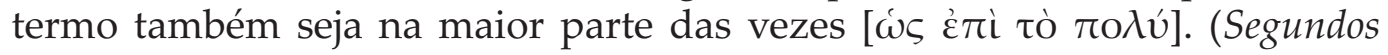
Analíticos II 12 96a 5-15).

Na Metafísica, há um exemplo diferente:

É preciso que a coisa seja determinada como ocorrendo sempre ou no mais


bom para os que tem febre, no mais das vezes; mas não se poderá indicar os casos excepcionais, dizendo em que momento o efeito do hidromel não se produz [...] enquanto o acidente está fora do sempre e da maioria das vezes. (E 2 1027a 20-25).

Ou ainda, "que, por exemplo, faça frio durante a canícula, não acontece

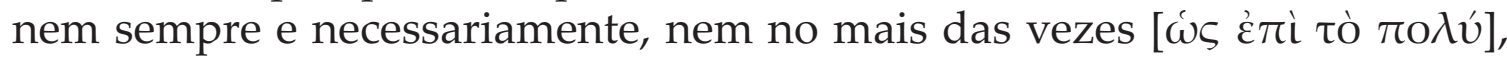
isto pode apenas acontecer às vezes". (Metafísica k 8 1064b 35). ${ }^{22}$

Os dois primeiros exemplos são muito semelhantes por apresentarem casos de conhecimento científico do frequente: o primeiro se refere à ocorrência de barba no homem e o segundo se refere à cura da febre pelo hidromel. Ambos os exemplos tratam de objetos de natureza mutável, e, por isso, que ocorrem quase sempre, diferentemente do que é necessário sem mais, imutável e eterno, entretanto, mais diferente ainda daquilo que ocorre por acaso. As condições do que ocorre por acidente ou por acaso não podem ser determinadas previamente, pois se tal determinação fosse possível, os acasos e os eventos acidentais seguiriam alguma regra, algum padrão. As condições dos eventos frequentes, por outro lado, são passíveis de previsão. O último exemplo é igualmente elucidativo, mas por via negativa, pois apresenta o que não ocorre sempre nem frequentemente, referindo-se, portanto, ao acidental. Dessa forma, fazer frio em um período meteorológico muito quente, e.g. no início do verão, é algo possível, mas nem necessário nem frequente. Tal exemplo é elucidativo especialmente por clarear a diferença entre o frequente e o acidental. Outro exemplo apresentado por Aristóteles do que ocorre por acaso se encontra na Física:

Alguém que recobra um empréstimo poderia ter vindo em vista do retomar o dinheiro, se soubesse; no entanto, não foi em vista disso que ele veio,

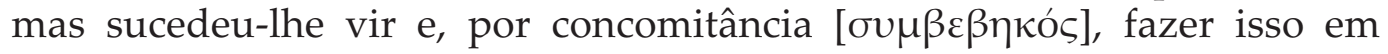

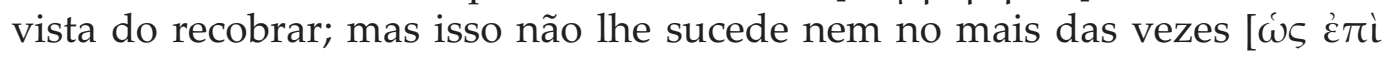

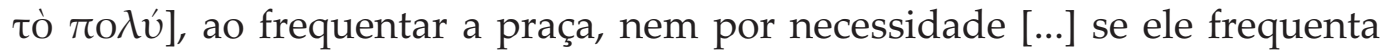
o lugar sempre ou no mais das vezes fazendo cobranças, não se diz [que faça isso] por acaso. (II 5 196b 20).

O exemplo é intuitivo e dispensa explicação. No entanto, trazê-lo à discussão auxilia a percepção da diferença entre acaso, necessidade sem mais e

${ }^{22}$ A mesma ideia com o mesmo exemplo é encontrada também em Metafísica E 2 1026b 30. 
frequência. $\mathrm{O}$ exame das causas que caracteriza o conhecimento científico depende de uma análise desses tipos de ocorrência, pois o acaso não pode ser causa nem do que ocorre sempre, nem do que ocorre quase sempre. ${ }^{23}$ Do acaso, do acidente, não há ciência. ${ }^{24}$

Em Segundos Analíticos I 6 74b 5-10 Aristóteles apresenta o caráter necessário das premissas que compõem a ciência. A oposição apresentada é entre necessário e acidental, e a ciência se refere ao que é necessário. Todavia, o que é necessário admite dois sentidos, ambos contidos no tipo de predicado por si. Em um primeiro sentido, o sujeito contém o predicado, o predicado é parte da essência do sujeito, como na atribuição do predicado animal ao sujeito ser humano. Em um segundo sentido, há um predicado por si, se o predicado se encontra no sujeito e o sujeito se encontra na definição do predicado, e.g. na atribuição do predicado ímpar ao sujeito número. Dito de outra forma, os predicados por si que interessam à ciência são aqueles que ou contêm os seus sujeitos, ou estão contidos em seus sujeitos. Os predicados que não se encaixam em nenhum desses dois sentidos são acidentais.

Em Tópicos I 5, ao apresentar os tipos de predicáveis, Aristóteles define o predicado acidental como qualquer predicado que não apresente a essência, o gênero ou a propriedade, e ainda, como um atributo que pode tanto pertencer quanto não pertencer a seu sujeito. ${ }^{25} \mathrm{Na}$ Metafísica, Aristóteles esclarece o que entende pelos termos necessário (D 5 1015a) e acidente (D 30 1025a 15-35). O principal sentido de necessário, ao qual todos os demais podem ser subsumidos, é aquilo que não pode ser diferente do que é. Quanto ao sentido primário de acidente, tem-se que é o que pode ser predicado de algo e que não é nem sempre afirmado nem frequentemente afirmado. Tal sentido apresenta, mais uma vez, a oposição entre, por um lado, o que é acidental e, por outro, o que é sempre ou frequentemente. O exemplo é esclarecedor:

Se, cavando um fosso para plantar uma árvore, se encontra um tesouro, é por acidente que aquele que cava o fosso encontra um tesouro, pois isso não é nem uma sequência necessária, nem sua consequência, e não é no


um tesouro. Vamos supor ainda que um músico seja branco: como esta

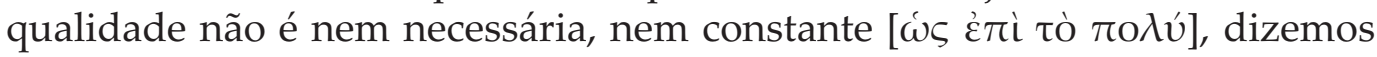
que é um acidente. (Metafísica D 30 1025a 15-25).

${ }^{23}$ Cfe. Física II 5 196b 10.

${ }^{24}$ Cfe., por exemplo, Metafísica E $21026 \mathrm{~b} 1$.

${ }^{25}$ Cfe. Tópicos I 5 102b 5. 
Encontrar um tesouro, nesse caso, é acidental, fortuito ou mero acaso, porque não se o estava procurando, mas querendo plantar uma árvore. Da mesma forma, um músico pode tanto ser branco quanto não o ser, diferente do que é sempre ou frequentemente, isso porque a brancura é indiferente para que alguém seja músico; não há relação causal entre ser músico e ser branco, assim como não há relação causal entre cavar um fosso para plantar uma árvore e achar aí um tesouro.

Angioni, em comentário à Física (2009, p. 376), escreve que, para Aristóteles, os fenômenos da natureza apresentam necessidade, mas não no sentido de um determinismo de séries causais implacáveis, pois se trata de necessidade acoplada ao mundo natural, não se confundindo, portanto, com a necessidade dos entes eternos. Angioni acrescenta que:

Há relações necessárias entre as qualidades essenciais dos elementos e certos fenômenos. No entanto, como foi aqui descrita, tal necessidade se dá apenas em linhas gerais, porque se circunscreve ao domínio das coisas materiais, que podem ser de outro modo e não estão a todo o momento em sua plena efetividade. Essas relações necessárias envolvem uma conjunção de fatores sujeitos à contingência dos entes materiais. (2009, p. 351).

Tais fatores sujeitos à contingência podem, por exemplo, impedir a atualização da teleologia própria a um fenômeno natural e, dessa forma, tal fenômeno não vai ocorrer. A necessidade que "se dá apenas em linhas gerais" é diferente da necessidade que vigora no domínio dos seres eternos, devido à matéria da qual esses fenômenos naturais são constituídos. Nesse sentido, poder-se-ia falar que, no âmbito dos fenômenos naturais, haveria uma "necessidade fraca", não em si mesma, mas quando comparada à necessidade "forte" e implacável que rege os seres eternos. ${ }^{26}$ Todavia, ambas são necessidades; ambas são objetos da ciência aristotélica. O conhecimento científico é aquele conhecimento demonstrado através de premissas que são verdadeiras, imediatas, necessárias, mais conhecidas que a conclusão e próprias ao gênero de coisas que se quer demonstrar. Mas há lugar na ciência aristotélica para aquilo que ocorre no mais das vezes. A inserção de ocorrências no mais das vezes parece antes, nesse caso, resolver um problema do que criar uma contradição. Ela possibilita que o conhecimento da natureza física seja um conhecimento científico.

\footnotetext{
${ }^{26}$ Escreve Zingano (2008) que, no campo da ética, os objetos eternos "que não podem ser de outro modo", são os primeiros a serem excluídos do âmbito deliberativo. No grupo dos objetos eternos, estão incluídos "o universo e sua ordenação [...] bem como os objetos matemáticos". (p. 175). Os segundos a serem excluídos são os que "sofrem mudança [...]. Homens, por exemplo, morrem, e a morte lhes ocorre inevitavelmente, portanto necessariamente; os cabelos dos homens, porém, tornam-se nas mais das vezes grisalhos (pois alguém pode perdê-los antes, ou morrer). Este segundo grupo inclui assim uma causa natural sob o registro das mais das vezes, cuja exceção se faz por acidente, sem destruir o fato que o mesmo fenômeno se engendra do mesmo modo." (p. 176).
} 


\section{Referências}

ANGIONI, L. Relações causais entre eventos na ciência aristotélica: uma discussão crítica de Ciência e Dialética em Aristóteles, de Oswaldo Porchat. Analytica, vol. 8, n. 1, 2004, p. 13-25.

ARISTÓTELES. De Anima. Apresentação, tradução e notas de Maria Cecília Gomes dos Reis. São Paulo: Ed. 34, 2006.

Éthique à Nicomaque. Traduction et présentation par R. Bodéüs. Paris: GF Flammarion, 2004.

Física I e II. Prefácio, tradução, introdução e comentário de Lucas Angioni. São Paulo: Unicamp, 2009.

Les Premiers Analytiques. Traduction nouvelle et notes par J. Tricot. Paris: Librairie Philosophique J. Vrin 6, Place de La Sorbonne, 1966.

Les Topiques. Traduction nouvelle et notes par J. Tricot. Paris: Librairie Philosophique J. Vrin 6, Place de La Sorbonne, 1997.

. L'éthique a Nicomaque - Tome II. Introduction, traduction et commentaire par R-A. Gauthier et Y. Jolif. Éditions Peeters: Louvain-la-neuve, 2002.

. Nicomachean Ethics. Translated with introduction, notes, and glossary, by Terence Irwin. 2a ed. Indianapolis/Cambridge: Hackett, 1999.

. Physique. Traduction et presentation por Pierre Pellegrin. Paris: GF Flammarion, 2002.

. Retórica. Edición del texto con aparato crítico, traducción, prologo y notas por Antonio Tovar. Madrid: Centro de Estudios Constitucionales, 1990.

Seconds Analytiques. Introduction, traduction, notes, bibliographie et index par Pierre Pellegrin. s/l: GF Flammarion, 2005.

. Métaphysique. Nouv. éd. Paris: Librairie Philosophique J. Vrin. (Bibliothèque des textes philosophiques), 1953.

BARNES, J. The Complete Works of Aristotle - the Revised Oxford Translation. 2 vols. Princeton: Princeton University Press, 1995.

. Vida e obra. In: BARNES, J. (org.) Aristóteles. Trad. de Ricardo Hermann Machado. São Paulo: Ideias e Letras, 2009, p. 29-58.

FERREIRA, P. Notas sobre a definição do enunciado asseverativo em Aristóteles, [Online]. Journal of Ancient Philosophy, v. V, Issue 1, 2011, p. 1-14. Disponível em: http:// www.filosofiaantiga.com/documents/paulo-revisto.pdf. Acesso em: 30 outubro 2012.

HANKINSON, R. J. Filosofia da ciência. In: BARNES, J. (Org.). Aristóteles. Trad. Ricardo Hermann Machado. São Paulo: Ideias e Letras, 2009, p. 155-190.

PORCHAT, O. Ciência e Dialética em Aristóteles. Marília: UNESP, 2001. 
Sobre a degola do boi, segundo Aristóteles: réplica à Lucas Angioni. Analytica, vol. 8, n. 1, 2004, p. 89-142.

ROSS, S. D. Aristóteles. Lisboa: Publicações Dom Quixote, 1987.

ZINGANO, M. Aristóteles: tratado da virtude moral; Ethica Nicomachea I 13 - III 8. São Paulo: Odysseus, 2008.

Endereço da Autora:

e-mail: jaquelinestefani@yahoo.com.br 